\title{
The Roma and Education Against Social Exclusion
}

\author{
Gisela Redondo* and Mimar Ramis
}

\begin{abstract}
Department of Sociological Theory, Philosophy of Law and Methodology of Social Sciences, University of Barcelona, Diagonal 690, 08034 Barcelona, Spain
\end{abstract}

\begin{abstract}
Education is a key tool for social inclusion and upward mobility, specially referring to the case of minority groups as they have traditionally suffered situations of exclusion. School thus plays a key role as the institution that can contribute to the educational success and social inclusion of these social groups. In this article we will introduce some conclusions from two investigations conducted for and with the Roma community in order to identify barriers to be overcome and successful elements to promote their educational and social inclusion. The analysis of the Roma women's role through the Brudila Callí project illustrates how they are a key agent for the promotion of education as a successful tool for inclusion of the whole Roma community. We will also go in depth in the analysis of the research process in order to present how the critical communicative methodology has also been an essential element that is contributing to the educational success of the Roma community.
\end{abstract}

Keywords: Roma, education, inclusion, community participation.

\section{INTRODUCTION}

In this article we start from the contributions made by various research projects carried out by the CREA research centre (Centre of Research in Theories and Practices that Overcome Inequalities) from the University of Barcelona. These projects focused on the study of the situation of the Roma community with the active participation of the Roma community. We will introduce how these investigations have contributed through their research process to shed light upon situations of inequality faced by this social group and the ways to overcome them.

Therefore, we will analyse which are the factors that have worked as barriers and hindrances for the social inclusion of these communities on the one hand, and which are the elements that have contributed to overcome these hindrances, on the other. To do so, two research projects are analysed: Brudila Calli: Roma women against exclusion. Overcoming the truancy and school failure of Roma girls and adolescents (2001-2004) ${ }^{1}$ funded by the Women's Institute of the Ministry for Employment and Social Affairs is a research project that arose as a result of the need to identify and state solutions to overcome the situation of educational absenteeism and school drop-out of Roma girls and adolescents, as a means to overcome the social and economic exclusion of this social group [1].

Furthermore, we will also refer to WORKALÓ. The creation of New occupational patterns for cultural minorities. The Gypsy case - RTD. FP5. DG XII [2]. Improving the Socioeconomic Knowledge Base. (2001-2004), a project funded by the European Commission's 5th Framework Programme which

\footnotetext{
*Address correspondence to this author at the Department of Sociological Theory, Philosophy of Law and Methodology of Social Sciences, University of Barcelona, Diagonal 690, 08034 Barcelona, Spain; Tel: 934039853;

E-mail: gredondo@ub.edu
}

${ }^{1}$ Brudila Calli: Las mujeres gitanas contra la exclusión. Superación del absentismo y fracaso escolar de las niñas y adolescentes gitanas, Ministerio de Trabajo y Asuntos Sociales - Instituto de la Mujer, Plan Nacional I+D+I. goal was to analyse the abilities and skills developed by the Roma community that were actually requested in the Information Society and their potential for inclusion in the labour market.

These projects are framed within the research lines developed by CREA. These include the study of educational practices which contribute to overcoming social inequalities; research with the Roma population as an ethnic minority which has historically faced a situation of exclusion; and, finally, the gender perspective.

The characteristics of the Information Society make academic knowledge acquired in contexts within formal education, and, more specifically, within schools, a priority. However, we see that the education system has traditionally only taken the voices of the majority culture into account. This has meant that the Roma community, as other minority groups in our societies, has not been represented, its culture has not been taken into account provoking the rise of a distance between this community and the school that has been difficult to surmount. In these educational institutions that do not listen to them and thus do not represent them, the loss of meaning is a major issue. This situation fosters high rates of truancy and school failure for the Roma in general, which increase in the case of Roma girls and young women. This means that the social exclusion faced by this group continues to be reproduced. Added to the lack of academic education, there are two other factors which accentuate this situation in the case of Roma women: the fact of being women and the fact of being Roma.

Roma women are well aware of the fact that one of the most significant causes of the social and economic exclusion they face is derived from their lack of presence or even their failure in the current education system. They are also conscious of their great potential to influence transformations in their community and how by accessing education they can contribute to overcoming that exclusion.

The projects discussed in this article refer to investigations oriented towards finding mechanisms that avoid the exclusion 
from the dynamics of social promotion within the Information Society of the different social groups. The communicative methodology has been used not only as the basis for theoretical development but also due to it being essential for intellectual coherence. As we will see further on, through the use of this methodology, children and adolescents, as well as mothers and other Roma women, can take on an active and egalitarian role throughout the research process. This functioning has contributed to put forward rigorous statements about the possible solutions to the existing situations of exclusion coming from the very actors, taking their opinions into account and thus complementing the scientific knowledge about their situation and the ways to overcome it.

\section{SCHOOL, EDUCATION AND SOCIAL INCLUSION}

In the Brudila Calli project the opinions and proposals of Roma women themselves were gathered in order to set out the theories and practices that contribute to overcome the situation of exclusion from education which Roma girls and adolescents experience. Ensuring success at school for Roma girls and adolescents aims to provide Roma women with greater autonomy in the future, both inside and outside their community, in order to put an end to their social and economic exclusion.

This research started from the premise that school can contribute to changing situations of inequality. The knowledge that is provided at school constitutes a key element in order to access the Information Society, therefore ensuring academic success for everyone, which will help to avoid exclusion and decrease social inequalities. Specifically, the contribution of this project lies in the importance of the active implication of Roma women and girls as leading subjects in the definition of the transformative factors which contribute to it.

Our theoretical basis and our research practice are based on this premise that acknowledges schools' power of transformation as a means for social change. In that sense, the significance of the Brudila Calli project resides in this concept of school as a tool to overcome social inequalities: ensuring that Roma children and adolescents do not drop out of school is synonymous with providing these women with mechanisms for transformation. They will in this sense, define the meaning behind any social change which they want to experience based on their own identity, and on their creative and transformative capacity.

For a long time the causes behind school failure within the heart of certain social groups were attributed to individualrelated issues (intelligence quotient, a lack of interest) or to context-related issues (family, the environment). However, it can be stated that these are simplistic, partial, and stigmatised explanations, as they do not take certain variables into account which entail other types of factors related to this school failure.

Amongst the theoretical contributions on this field of study we find contributions stating that school is co-responsible for social inequalities and does contribute to change them, correcting the controversy of the articles on the schools and equal opportunity written in the United States in 1972. Specifically, the works entitled Inequality by Christopher Jencks [3] and The Schools and Equal Opportunity by Mary Jo Bane y Christopher Jencks [4]. One of their conclusions was widely disseminated and very influential: Differences between schools have a very small impact on what happens to students after graduation [4]. Subsequently, any progressive orientations in policies and social movements in the field of education were discredited.

Furthermore, it was also stated by these authors that the results imply that school reform would never have a significant influence on the degree of inequality between adults [4]. As was to be expected, the most enthusiastic defenders of this thesis were on the one hand the conservative powers which wanted to eliminate educational policies in favour of equality and on the other, those non-scientific authors who followed mediocre theoretical perspectives such as the reproductive model. Accordingly, the evidence of Jenks' statements inaccuracy was quickly pointed out by many authors and this soon began to be recognised by Jencks himself. Amongst the abundant literature written on this issue, we will only pinpoint some of the significant facts.

For example, Jencks based his work on the study of individual differences, since he considered that they were much greater than those between groups (black versus white, etc). While the human capital theorists placed an emphasis on the impact of educational investment on the group, Jencks focused on the individual. These different perspectives were working on the assumption that with educational tools individual differences are not combated though group differences are. In the same issue of the Harvard Educational Review, in February 1973, Jencks already began to backtrack on the position he maintained in his recent successful publication [5]. Even though he did not yet recognise any significant lack of accuracy in Inequality, he did begin to place an emphasis on some of its elements which in fact were oriented towards questioning the fundamental thesis of the book. Finally Jencks completely discredited his thesis set out in Inequality and his subsequent work improved in relation to previous work, moving closer to theorising on how school could overcome situations of social inequality.

Based on overcoming these premises, the three hypotheses used as the basis for the Brudila Calli project were as follows:

- School is an agent that transforms the situation of exclusion and the problems of coexistence: in school, people are able to acquire the tools which are necessary in order to achieve a certain degree of autonomy and to access the different areas of the Information Society. At the same time it is a place where people from different cultures can meet each other promoting a mutual knowledge, favouring coexistence among everyone.

- $\quad$ Roma women are active subjects capable of creating and thus transforming, they are not objects to be transformed: Roma women have developed their own transformative factors throughout history. In order to provide solutions to the topic being dealt with, it is essential to rely on the implication of Roma women, based on their life experience and their own point of view of the situation.

- Good practices are based on the skills of the participants: the competences of the participants such as Roma people and women were used as the basis for this. These are competences which they have developed and increased throughout their lives.

Thus the following general objectives were set out: developing theories and practices which overcome the exclusion 
of girls and female adolescents from the educational field, also overcoming coexistence problems at the same time; gathering the voices of Roma women in order to set out the transformative factors which are contributing to education through Roma women's movements and organisations; and providing theoretical elements about how to make intercultural dialogue possible. The specific objectives also included: school success for Roma girls and adolescents, transforming the situation of exclusion of this collective; as well as intercultural dialogue and gender equality.

Over the three years in which the Brudila project was carried out, the causes which lead Roma girls and adolescents to drop out of school were studied, and educational processes which take their cultural and gender characteristics into account and respond to their needs and interests were evaluated. In that way processes of continuing education were promoted in order to encourage the aspirations and expectations of this social group. The dialogue among women and also between men and women from the same culture, or from different cultures on egalitarian terms was promoted, always respecting the differences without intending to address Roma women as mere objects to be transformed.

PROJECTS FOR AND WITH THE ROMA COMMUNITY. CRITICAL COMMUNICATIVE METHODOLOGY

All of this was carried out while taking the voices of Roma women into account, them being active subjects of their own transformation, involving the community in general, including girls, family members, teachers...both regarding the very development of the project, as well as regarding its objectives.

In relation to the WORKALÓ project, its main objective was to carry out a European analysis of the situation of Roma people, defining strategies and political recommendations for their inclusion into the labour market, contributing to social cohesion. However, we do not aim to underline the results obtained from this research here, but rather to focus on the impact it had and still has on Spanish and European society as a result of the participation of Roma people and the inclusion of their voices.

Actually, one of the most significant contributions of the WORKALO project was the methodology that was used; the development of the critical communicative methodology in order to analyse the reality of cultural groups. Starting from the design of the analysis to the results and the political recommendations, it was possible to rely on the direct participation of the Roma community (through their European institutions, their NGO's and their position as citizens). The social utility of the research is in fact based on this participation, on the incorporation of the voices of the protagonists into the reality being researched, and on their interpretations and interaction [6]. The researchers and those being researched carry out a shared reflexive analysis through intersubjective dialogue on egalitarian terms.

Inter-subjective dialogue between scientists, academics and Roma people and their associations materialised in very different ways in this project. One of these was through the seminars organised throughout the WORKALO project in the participating countries. One particularly significant example took place in the CADIS seminar in March 2004 in Paris. CADIS (Centre d'Analyse et d'Intervention Sociologiques) is the research centre for the EHESS (l'École des Hautes Etudes en Sciences Sociales) in Paris. It is one of the most recognised research centres in Europe as far as the study of migration is concerned. The centre was founded by Alain Touraine and his former director was Michel Wieviorka. Both are recognised authors who work in the area of cultural identity and migration and who participated as speakers in the aforementioned seminar [7].

As a result of this intersubjective dialogue, the voices of Roma people are becoming more recognised every day, as well as more valued and more incorporated into the international scientific community. Proof of this is the publication of an article written by two members of WORKALO's research team -one of whom is Roma- in the most prestigious educational journal, the Harvard Educational Review [6]. The article, entitled "Why Romà do not like mainstream schools: voices of a people without territory" describes the need to research minority cultural groups such as the Roma people using a communicative methodology, as well as the impact and scientific nature of the research carried out following this perspective.

Another example proving the scientific and social use of the communicative methodology can be found in the conference held on the $23^{\text {rd }}$ and $24^{\text {th }}$ of October 2001 in Barcelona Science Park, entitled Cambio Educativo y Social III: Mujeres y transformaciones sociales [Educational and Social Change III: Women and social transformation]. The presence of Judith Butler, the most highly quoted international feminist author, stood out at this conference as did the presence of Lídia Puigvert and Elisabeth Beck-Gernsheim [8]. At the same time, non-academic women also attended the conference. Among them were cleaners and seamstresses etc, whose contributions are currently creating the basis of the new feminism, dialogic feminism. One example of this is the fact that Roma women also participated in the discussion along with these academics. During the debate with these women Judith Butler stated that: "Roma people are clearly excluded, but Carmen (one of these women) is constantly fighting against this situation. I think that this is a remarkable example of empowerment; she doesn't know how to read, but she has a lot to say and a lot to do". In an email sent to CREA after the conferences she stated: "It was a beautiful and moving experience, and it will change me and my work... you have returned me to my most basic sense of why feminist work is urgent, moving, inspiring". 2 This is further proof of the impact that the voices of Roma women are having on science, influencing current theoretical re-structuring as well as policies and social, economic and educational actions. It is only necessary to create spaces for their voices not to be silenced in debates about their own people, so they can be expressed and included in an egalitarian dialogue.

As far as the impact achieved through this research is concerned, it should be pointed out that the final results of the WORKALO project were presented before various Europarliamentarians, advisors, Council of Europe representatives, and representatives of Roma associations among others, on the $29^{\text {th }}$ of September 2004, in the Eastman building in the European Parliament in Brussels.

As part of this presentation, a Roma woman, who was also a member of the Advisory Committee for the project, emphasised the importance of education in order to break down the circle of

\footnotetext{
${ }^{2}$ Accessible online here: www.pcb.ub.es/crea/es/gdona_es.htm\#jornades.
} 
social exclusion which her population is facing. After her speech, a Spanish member of parliament who participated in the event made a public commitment to the Roma woman to bring a proposal for the recognition of the Roma population and their culture before the Congress of Deputies in Spain during that specific term. ${ }^{3}$

On the $7^{\text {th }}$ of April 2005 Josep Andreu fulfilled his promise. ${ }^{4}$ In the proposal of law presented before the plenary session related to the recognition of the rights of the Roma community, the Spanish government was urged to:

\section{c) Defend the full recognition of the identity, culture and language of the Roma population as being European, before the European Union. In that sense, respect for this identity, culture and language by the current members of the European Union will be defended, and it will also be an essential prerequisite for the entrance if new members (Official Bulletin for the General Courts, 15th of April 2005: 43).}

In the same Official Bulletin the European Union was asked to do the same:

\section{It is precisely due to their mainly dispersed nature across Europe and the lack of their own state, that should be a reason for the European Union itself to recognise their identity and supports their rights (p. 43).}

After 600 years and with more than 600.000 Roma living in Spain, this population was recognised as constituents of our country.

A Roma female parliamentarian also attended the WORKALO conference in the European Parliament, and was in charge of presenting a Resolution on the situation of the Roma population in the European Union on the $25^{\text {th }}$ of April 2005 in which the Council of Europe, the European Commission and the member states and candidate countries were asked to consider the recognition of the Romani population as a European minority amongst other issues. ${ }^{5}$ This same resolution contained the conclusions and orientations from the WORKALO project which were presented in Brussels and published in the Guía de propuestas politicas para la inclusión laboral de la comunidad gitana en Europa [Guide for political proposals for the labour inclusion of the Roma community in Europe]. This is proof of the social and political impact of the research carried out following the communicative methodology, in which the voices of the researched people are included throughout the whole process, improving thus the reached scientific results achieved.

Finally on the $27^{\text {th }}$ of September 2005, a year after the meeting in Brussels, the law proposal related to the Recognition of the Roma population was approved unanimously in the Congress of Deputies. The result was 319 votes in favour, 0 abstentions, and 0 votes against, with a notable presence in the room of representatives of the Roma population from different parts of Spain.

${ }^{3}$ Proceedings of the Conference on the Workalo RTD project. September 29, 2004. European Parliament. Brussels. Accessible on-line here: www.neskes.net/workalo/proceedings.pdf

${ }^{4}$ Accessible on-line here: www.pcb.ub.es/crea/es/noticia2_es.htm.

${ }^{5}$ European Parliament, P6_TA-PROV(2005)0151.
The theoretical and methodological options in our work maintain the same communicative approach which at the same time follows the dialogic orientation of society as well as the current research in the field of the social sciences. The communicative methodology is being developed by CREA in its research projects, mainly in the Framework Programme for Research and Development of the European Commission and in the Spanish R+D National Plan.

This methodology goes beyond previous paradigms because it takes into account the interpretations of the people who are "being researched", who provide different knowledge regarding the reality being researched than that provided by the research team. Greater plurality in terms of the definition of scientific knowledge implies a greater rigour and objectivity in that same knowledge. Thus, in the case of disadvantaged groups, noncommunicative methodologies, since they do not include their voices, do not achieve a true comprehension of the issues being dealt with.

For example, traditional explanations of school drop out and school failure amongst Roma students provided by certain authors utterly contradict what Roma women themselves feel and express in researches such as Brudila Calli. The latter's research process included the participation of Roma girls, adolescents and women who have offered their testimonies through interviews and life stories were asked to corroborate the analysis and the results found by the research team as a means of guaranteeing the interpretations and analyses done by the scientific team. On the other hand, two advisory committees that collaborated in the research were also set up: one consisted of Roma girls, and the other of Roma women, some of them were participants in Roma women's associations while others were not.

As a result, and based on the communicative methodology, greater objectivity is achieved and at the same time the link between theory and practice is guaranteed. This is necessary in order to provide transformative elements which are appropriate to the reality that is being analysed.

\section{CONCLUSIONS: EDUCATIONAL PROPOSALS}

The Brudila Calli research project revealed that the explanations for the school failure of Roma girls and adolescents which focus on individual factors (intelligence quotient, a lack of interest) or on environmental factors (the family, the environment) are biased. They do not take into consideration the voices of the people being affected by this, and they facilitate stigmatisation, which thereby reinforces exclusion. Subsequently, they provide with partial information and unfounded proposals that far from contributing to overcome the situation of exclusion suffered by these social groups, it could be worsening it.

Roma families, like all families, want the best for their children, and each generation fights for the world to be a better place than the one which they came into themselves. In this context, research focused on the reflections and opinions of Roma women proves that their main concerns relate to identity and education issues. They know that education is a priority for their children and for the Roma people as a whole, and for that reason they ask for schools which do not identify exclusively with the hegemonic culture, but schools in which they can maintain their Roma identity. 
Thus, despite the clear support Roma women provide their children with in order for them to receive quality education; it is within the educational system itself that more exclusionary factors are found, especially due to existing prejudices and the rejection of non-hegemonic identities. Roma families value education as a priority, but are not satisfied with an educational institution in which their culture and identity is not represented, which does not provide the learning necessary for the future employment, and in which they are not listened to, and their interests and needs are not taken into account.

A school that identifies exclusively the majority culture is jeopardising the cultural identity of the Roma community contributing to the rejection of schooling with eventual social exclusion as the major consequence.

Connected with these reflections, some proposals are put forward which are based on the research carried out. Firstly, the importance of making the Roma culture more visible in schools is pointed out. This can be done by:

- Introducing Roma culture through the curriculum

- Including Roma adults into the school everyday practice, either in areas for participation or areas for decisionmaking, as volunteers, teachers, collaborators.

On the other hand, the analysis carried out demonstrates the impact of the shift from primary to secondary school at the age of twelve. It is a moment which is especially risky as far as school drop out is concerned even more so in the case of girls. Their opinions prove the fear which is generated in relation to the idea of secondary school. Changing this idea, opening up doors, and facilitating knowledge of and once again participation in secondary schools is another action to be carried out in order to promote the success and continuity of Roma girls in education. Helping groups of girls and boys who went to primary school together to continue to be together in secondary, and fostering the proximity of schools to the community's neighbourhood, are also measures which promote families and female pupils to be able to continue to do what they are asking to do: study.

Finally, throughout these investigations, the importance of instrumental learning and positive role models was also underlined. In the case of the Brudila Calli project, we refer to the need to guarantee instrumental learning for all children, through a maximum number of activities and educational resources. Lowering expectations and decreasing learning in Roma children's schooling generates a lack of motivation and a loss of meaning as far as their school pathway is concerned. In the case of positive role models, there is a need to promote interaction with members of one's own community, people who have accessed higher educational levels and participated in them successfully.

In short, research has confirmed the hypotheses set out and has also provided guidelines and proposals to be reflected and acted on in our day to day educational practices. This contributes to give the research in the social sciences the social use it is being demanded as return. Identifying successful actions in order to inform public policies and thus contributing to social cohesion is a key goal of this scientific domain. The review presented here has shown how, through the inclusion in the scientific research process of the Roma community in egalitarian terms, better results and more useful guidelines for political actions are achieved.

It seems essential thus that educational research continues working with these scientific criteria in order to achieve the best results and subsequently granting the investigations with the necessary social utility. If we are to contribute to the further development of egalitarian pedagogy as well as improving educational practices in multicultural contexts, this ought to be a core guideline to be followed and further developed.

\section{ACKNOWLEDGEMENT}

None declared.

\section{CONFLICT OF INTEREST}

None declared.

\section{REFERENCES}

[1] CREA. Brudila Callí: Roma women against exclusion. Overcoming the truancy and school failure of Roma girls and adolescents. Women's Institute of the Ministry for Employment and Social Affairs; 2001-2004 [In Spanish].

[2] CREA. WORKALÓ. The creation of new occupational patterns for cultural minorities. The Gypsy case. Brussels: European Commission, DG XII; 2001-2004.

[3] Jencks C, Smith M, Acland $\mathrm{H}$, et al. Inequality. A reassesment of the effect of family and schooling in America1972. New York: Basic Books.

[4] Bane MJ, Jencks C. The schools and equal opportunity. Saturday Review of Education. 1972;38 (LV):37-42.

[5] Jencks C. Inequality in Retrospect. Harvard Educational Review. 1973(43):138-64.

[6] Gómez J, Vargas J. Why Roma do not like mainstream schools: voices of a people without territory. Harvard Educational Review. 2003;73:559-90.

[7] Touraine A, Wieviorka M, Flecha R, et al. Knowledge and Identity. Voices of cultural groups in social research. Barcelona: El Roure; 2004 [In Spanish].

[8] De Botton L, Puigvert L, Sanchez, AM. The inclusion of other women: Breaking the silence through dialogic learning. Dordrecht: Springer; 2005. 